\title{
Genetic diversity in the cycad Macrozamia riedlei
}

\author{
M. BYRNE \& S. H. JAMES \\ Botany Department, The University of Western Australia Nedlands, Western Australia, 6009
}

\begin{abstract}
The cycad, Macrozamia riedlei is a significant component of the native flora of southern Western Australia. It displays evolutionary conservatism not only in terms of its primitive morphology but also in the fact that only a single taxonomic species is recognized in this area. Microsporangia collected from 15 populations of the species were used to determine the extent and distribution of allozyme variation. The 14 loci studied showed high levels of polymorphism, an excess of heterozygotes relative to that expected under panmixia, some clinal variation but relatively low levels of interpopulational diversification. The level and distribution of diversity was similar to the average reported for conifers and angiosperm plants with similar life-history characteristics. These results contrast sharply with those reported in a similar study on $M$. communis, a cycad endemic to eastern Australia.
\end{abstract}

Keywords: cycad, genetic diversity, isoenzyme analysis, Macrozamia riedlei.

\section{Introduction}

Macrozamia riedlei (Gaud.) C.A. Gardn. is a member of the cycad family Zamiaceae native to southern Western Australia. The species is widely distributed from Jurien Bay in the north along the coastal region to Esperance on the south coast and is a significant and sometimes dominant component of coastal heath, woodland and forest vegetation. It is a vigorous and competitive lineage deriving from the Gondwanic preAngiosperm flora; it has retained primitive morphological features and has not been subjected to significant speciation in this region.

The evolutionary and taxonomic conservatism displayed by this cycad is perhaps surprising in view of the high levels of genetic diversity that may be expected in such a diploid $(n=9)$, dioecious, wind-pollinated, long-lived, perennial plant (Hamrick \& Godt, 1990, 1979). However, the level of genetic diversity within the species had not been ascertained. Indeed, there has been little interest in the population genetic structure of cycads until a recent study on $M$. communis, an eastern Australian species, which showed surprisingly low levels of genetic diversity (Ellstrand et al., 1990). The present study investigates the level and distribution of genetic variation within $M$. riedlei by an analysis of allozyme variation.

\section{Materials and methods}

\section{Sites and sampling}

Mature microsporophylls were collected from the cones of 9-15 male plants of $M$. riedlei from 15 populations in southern Western Australia, from Cataby to Walpole covering about $500 \mathrm{~km}$ of the species range (Fig. 1.). The microsporangia were scraped off the microsporophylls into small jars, separated from desiccant by filter paper, and stored at $-20^{\circ} \mathrm{C}$ until electrophoresis was performed.

\section{Electrophoretic analysis}

Eight to ten microsporangia were homogenized in

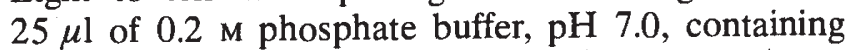
polyvinyl-pyrrolidone $\left(20 \mathrm{mg} \mathrm{ml}^{-1}\right)$, sucrose $(10 \%$ $\mathrm{w} / \mathrm{v})$ and bromophenol blue $\left(0.5 \mathrm{mg} \mathrm{ml}^{-1}\right)$ with a trace of NAD, NADP and dithiothreitol added just before use. The homogenate was absorbed onto three $3 \times 9$ $\mathrm{mm}$ Whatman No. 1 chromatography wicks which were inserted into 12.5 per cent starch (Sigma S4501) gels for horizontal electrophoresis. Two buffer systems were used to resolve nine enzymes.

1 A continuous tris citrate $\mathrm{pH} 7.0$ buffer (James et al., 1983) for 6-phosphogluconate dehydrogenase 


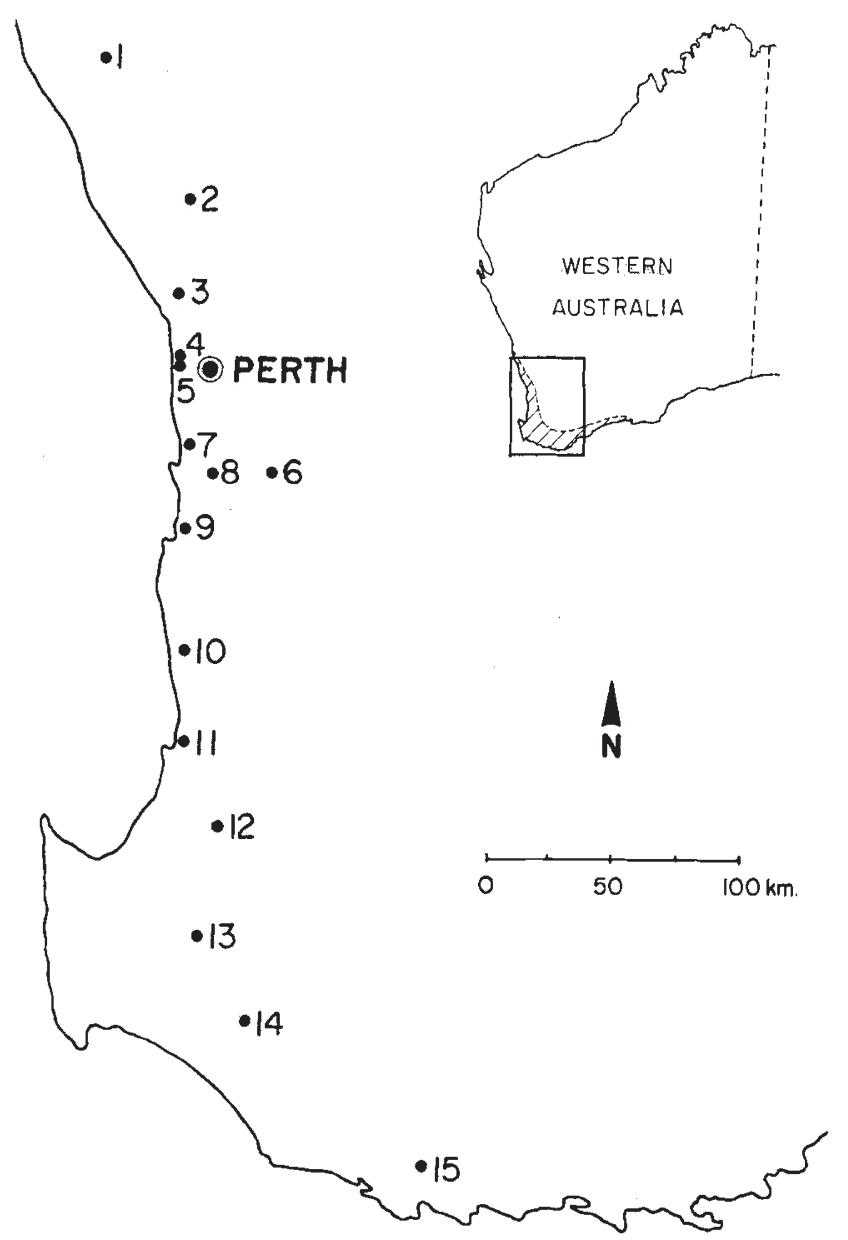

Fig. 1 Approximate range of $M$. riedlei in Western Australia and locations of sampled populations. Population names: 1 . Cataby; 2. Gingin; 3. Nowergup; 4. Raebold Hill; 5. Bold Park; 6. Gleneagle; 7. Henderson; 8. Wellard; 9. Mandurah; 10. Lake Clifton; 11. Bunbury; 12. Donnybrook; 13. Glenoran; 14. Nannup; 15. Walpole.

(6PGD), phosphoglucomutase (PGM), malate dehydrogenase $(\mathrm{MDH})$, glutamate dehydogenase (GDH), isocitrate dehydrogenase (IDH) and shikimate dehydrogenase (SDH).

2 A discontinuous lithium borate $\mathrm{pH} 8.2$ buffer (Moran \& Hopper, 1983) for phosphoglucose isomerase (PGI), alcohol dehydrogenase (ADH) and leucine amino peptase (LAP).

Staining recipes used were those of Richardson $\mathrm{et} \mathrm{al}$. (1986) for ADH, IDH, GDH, 6PGD, PGM and MDH; Vallejos (1983) for SDH and PGI; and Shaw \& Prasad (1970) for LAP except that $0.2 \mathrm{M}$ sodium phosphate, $\mathrm{pH} 5.5$, was used as the buffer instead of tris malate. As the material homogenized was mainly haploid pollen with only a small amount of diploid sporangial tissue, homodimer bands stained strongly while heterodimer bands stained faintly or were absent. This facilitated zymogram interpretation and only those loci which could be confidently interpreted were used in the study. Confirmation of zymogram interpretation through Mendelian analysis was not possible.

\section{Data analysis}

The Biosys-1 computer program of Swofford \& Selander (1981) was used to calculate the mean number of alleles per locus $(A)$, the mean number of polymorphic loci $(P, 0.99$ criterion), observed heterozygosity $\left(H_{\mathrm{o}}\right)$, Hardy-Weinberg expected panmictic heterozygosity $\left(H_{\mathrm{e}}\right)$, Wright's Fixation Index $(F$; Wright, 1969) and genetic distance (unbiased for sample size) ( $D ; \mathrm{Nei}, 1978$ ). A hierarchical cluster analysis was also performed using an unweighted pair-group method with arithmetic averaging (UPGMA), based on the unbiased genetic distance (Nei, 1978) measures. The Genestat-PC computer program of Lewis \& Whitkus (1989) was used to calculate the total gene diversity of each polymorphic locus $\left(H_{\mathrm{T}}\right)$, the mean gene diversity within populations $\left(H_{\mathrm{S}}\right)$, the mean gene diversity between populations $\left(D_{\mathrm{ST}}\right)$ and the relative degree of gene diversity between populations $\left(G_{\mathrm{ST}}\right)(\mathrm{Nei}, 1973$; Nei \& Chesser, 1983). In addition, an estimate of gene flow, $N m$, was calculated by the $F_{\mathrm{ST}}$ method (Slatkin \& Barton, 1989). $N$ is the number of individuals in the population and $m$ is the migration rate; hence $\mathrm{Nm}$ represents the number of immigrants per generation.

\section{Results}

Of the 14 loci assayed, 13 were polymorphic. The LAP locus was the only locus monomorphic in all populations and the ADH locus was polymorphic in the Lake Clifton population only. All other loci were polymorphic in at least four populations and four loci, 6PGD-2, PGI-2, SDH and MDH-1, were polymorphic in all populations. Allele frequencies for polymorphic loci are presented in the Appendix. The mean allelic diversity of populations and total allelic diversity measures are presented in Table 1 . The mean number of alleles per locus, $A$, the mean percentage of polymorphic loci, $P$, and the observed heterozygosity, $H_{0}$, all show a general increase in value through the populations in a north-south direction. The overall number of alleles per locus, $A(2.43)$, the percentage of polymorphic loci, $P(93 \%)$, and the expected panmictic heterozygosity, $H_{\mathrm{e}}(0.274)$, were very high when compared to mean values reported for 473 other plant species representing a wide range of life-history characteristics $(A=1.96, P=50.5$ per cent, 
$H_{\mathrm{e}}=0.149 ;$ Hamrick \& Godt, 1990). These diversity measures are also higher than the means reported for plants that are gymnosperms, long-lived woody perennials, outcrossed with wind pollination, or disperse seeds by gravity (Hamrick \& Godt, 1990)

Analysis for goodness of fit of genotype proportions to Hardy-Weinberg expectations yielded significant $\chi^{2}$ values at 35 of the loci within populations. There was an excess of heterozygotes in 18 of these samples. However, in the overall sample, 70 loci within populations exhibited an excess of heterozygotes while 40 exhibited a deficiency. This was significantly different from the 1:1 ratio that could be expected under random mating $\left(\chi_{[1]}^{2}=8.2 ; P<0.01\right)$. The expected heterozygosity was slightly higher than the observed heterozygosity for the samples taken in total (Table 1). This is a result of the Wahlund effect. When the average of the populations (which avoids the Wahlund effect) was taken, the $\mathrm{H}_{\mathrm{e}}$ value (0.238) was lower than $H_{\mathrm{o}}(0.263)$. The values of $F$ ranged from -0.847 to 1.000 with 87 of the 126 values estimated negative. The mean $F$ values of the populations are presented in Table 1. The total $F$ value across all loci in all populations has a small, negative value $(-0.079)$.

The mean estimates of total genetic diversity $\left(H_{\mathrm{T}}\right)$, the distribution of diversity within $\left(H_{\mathrm{S}}\right)$ and between $\left(D_{\mathrm{ST}}\right)$ populations, and the relative proportion of diversity between populations $\left(G_{\mathrm{ST}}\right)$ over all populations $\left(H_{\mathrm{T}}=0.295, \quad H_{\mathrm{S}}=0.268, \% G_{\mathrm{ST}}=9.2\right)$ were

Table 1 Mean parameters of diversity for populations and total diversity of all samples of $M$. riedlei. $A=$ mean no. of alleles. $\mathrm{P}=$ mean percentage of polymorphic loci $(0.99$ per cent criterion). $H_{\mathrm{o}}=$ observed heterozygosity. $H_{\mathrm{e}}=$ expected panmictic heterozygosity. $F=$ fixation index

\begin{tabular}{llllll}
\hline Population & $A$ & $P$ & $H_{\mathrm{o}}$ & $H_{\mathrm{e}}$ & \multicolumn{1}{l}{$F$} \\
\hline Cataby & 1.6 & 42.9 & 0.190 & 0.148 & -0.145 \\
Gingin & 1.6 & 50.0 & 0.195 & 0.202 & 0.118 \\
Nowergup & 1.7 & 57.1 & 0.234 & 0.207 & -0.014 \\
Raebold Hill & 1.5 & 42.9 & 0.188 & 0.163 & -0.115 \\
Bold Park & 1.6 & 57.1 & 0.260 & 0.206 & -0.177 \\
Gleneagle & 2.0 & 64.3 & 0.262 & 0.260 & -0.053 \\
Henderson & 1.8 & 71.4 & 0.264 & 0.237 & -0.053 \\
Wellard & 1.7 & 57.1 & 0.312 & 0.264 & -0.195 \\
Mandurah & 1.8 & 57.1 & 0.299 & 0.245 & -0.220 \\
Lake Clifton & 1.9 & 64.3 & 0.246 & 0.227 & -0.126 \\
Bunbury & 1.8 & 57.1 & 0.193 & 0.196 & 0.070 \\
Donnybrook & 2.1 & 71.4 & 0.357 & 0.316 & -0.115 \\
Glenoran & 2.1 & 71.4 & 0.319 & 0.305 & -0.026 \\
Nannup & 2.1 & 71.4 & 0.314 & 0.306 & -0.092 \\
Walpole & 2.0 & 64.3 & 0.306 & 0.282 & -0.038 \\
Total & 2.4 & 93.0 & 0.263 & 0.274 & -0.079 \\
\hline
\end{tabular}

similar to those for outcrossed, wind-pollinated plants $\left(H_{\mathrm{T}}=0.293, H_{\mathrm{S}}=0.259, \% G_{\mathrm{ST}}=9.9\right)$ reported by Hamrick \& Godt (1990).

Estimates of unbiased genetic distance $(D$; Nei, 1978 ) between all pair-wise comparisons of populations showed that the greatest genetic distances occurred between the Donnybrook and Raebold Hill populations (0.125) and between Donnybrook and Cataby (0.121), while zero genetic distance occurred between six pairs of populations (Gingin-Raebold Hill, Nowergup-Bold Park, Nowergup-Henderson, Nowergup-Mandurah, Bold Park-Henderson and Gleneagle-Mandurah). A dendrogram to illustrate the relationship between populations based on genetic distance is shown in Fig. 2. In general there is a correlation between the grouping of the populations in the dendrogram and their geographical distribution. An estimation of gene flow gave $N m=2.47$, a value which indicates substantial gene migration between populations (Slatkin \& Barton, 1989).

\section{Disussion}

In contrast with the low levels of allozyme diversity reported for $M$. communis (Ellstrand et al., 1990), $M$. riedlei exhibits very high levels of polymorphism when compared with a wide range of plant species and shows higher levels of allelic polymorphism than plants with similar life-history traits (e.g. long-lived, outcrossed, wind-pollinated or seeds dispersed by gravity; Hamrick \& Godt, 1990), including conifers. In this respect, $M$. riedlei is not a genetic relic, rather it maintains a richly diverse gene pool.

The level of polymorphism in the populations was higher in the south. The southern populations are associated with a cooler climate and higher annual rainfall, conditions which are possibly more representative of the lineage's Gondwanic region of origin.

The significant excess of samples which contained more heterozygotes than expected suggests a heterozygote advantage in survival. The females produce large seeds that generally fall around the maternal plant when the cone disintegrates, but can be dispersed up to $25 \mathrm{~m}$, at least, by possums (Burbidge \& Whelan, 1982). As a consequence of this limited seed dispersal, seedlings tend to grow in clusters in which competition for nutrients and space, not only with each other but also with the parent plant, may be pronounced. Allozyme heterozygotes may be preferentially selected in seedling competition.

Limited seed dispersal must also often result in sibling progeny growing in close proximity to each other and may be expected to lead to some inbreeding 


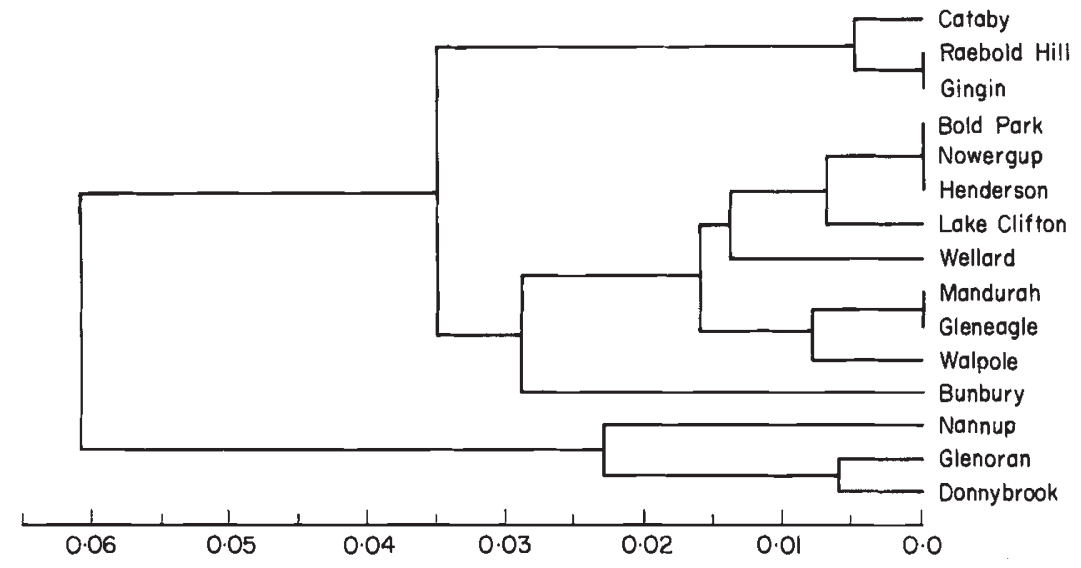

Fig. 2 Dendrogram showing relationships between populations of $M$. riedlei, based on UPGMA cluster analysis of genetic distance measures. due to matings between relatives. If arrays of deleterious recessives are variously linked to the allozyme marker loci, then this effect would enhance the discrimination between allozyme heterozygotes and homozygotes during seedling competition.

Inbreeding tends to result in high levels of population differentiation (Hamrick \& Godt, 1990). Significant levels of inbreeding may be expected to be generated in Macrozamia through its limited seed dispersal. However, the genetic distance between populations was low and the relative proportion of diversity between populations was similar to the average reported for outcrossed wind-pollinated plants (Hamrick \& Godt, 1990), which suggests that any such inbreeding does not occur with sufficient intensity to have an effect on population differentiation. Alternatively, it may be that the inbreeding effects are minimized by post-zygotic selection resulting in a heterozygote advantage. Note also that the occurrence of multiple archegonia in the prothallus of Macrozamia permits a level of polyembryony and post-zygotic competition between embryos in the developing seed. The intensity of this competition has not yet been documented, but comparable situations are of substantial importance in maintaining the genetic diversity of conifer populations (Ledig, 1986).

Gene flow may occur through both pollen and seed dispersal in Macrozamia but few studies have considered the relative effectiveness of pollen versus seed dispersal. Antonovics (1968) found that with lowselection pressures, seed dispersal was more effective at reducing population differentiation than pollen dispersal and suggested that, if pollen is abundant, an immigrant pollen grain will have little likelihood of effecting fertilization whilst an incoming seed would be as likely to reach maturity as a locally produced seed. In the present case, incoming seeds may have an advantage in that they are probably deposited away from the seed clusters that result from disintegrating cones and so have a reduced level of competition. In addition, immigrant pollen, whether it arrives by long-distance dispersal on wind currents, or from an established immigrant male, may be expected to carry a relatively unrelated array of recessive lethals linked with the marker allozyme loci so that its progeny will be favoured in embryo and seedling competition. The estimate of gene flow in $M$. riedle $i$ was high $(N m>1)$ and, combined with the low population differentiation and low genetic distance between populations, suggests that the combined effects of limited-seed dispersal, pollen dispersal by wind, outbreeding through dioecy and post zygotic selection against homozygosity has maintained a robust gene pool with little interpopulation differentiation.

The high levels of genetic diversity and low population differentiation in $M$. riedlei contrast markedly with the low levels of genetic diversity and high population differentiation reported for $M$. communis (Ellstrand et al., 1990). Ellstrand et al. (1990) attributed the pattern of diversity in $M$. communis to the effect of limited seed dispersal but did not take into account the effect of wind pollination in the species or heterozygote advantage. The study on $M$. communis analysed seedling leaf tissue whilst the present study on $M$. riedlei analysed microsporangia from adult male plants. If selection for heterozygous individuals operates through seedling development stages then lower levels of observed heterozygosity at the seedling stage and higher levels at the adult stage may be expected. However, the other measures of diversity in $M$. communis. $\left(A=1.61, P=50\right.$ per cent, $\left.H_{\mathrm{e}}=0.08\right)$ were also much lower than in $M$. riedlei. $M$. communis is one of 11 species of Macrozamia found in New South Wales and in some of these the process of ecogeographical speciation is considered to be incomplete (Johnson, 1959). The macrozamia lineage in eastern Australia is thus much more active in terms of its taxonomic diversification than in Western Australia. In Western Australia its robust gene pool is more or less continuously distri- 
buted over a large region of low relief and geological stability. Genetic diversity has accumulated within it, especially in its southern region where it enjoys an environment more comparable with that of its origin, but less so towards its more arid and demanding northern limits. On the other hand, in eastern Australia, Macrozamia inhabits a region which has undergone considerable geological activity since Gondwanic times and its habitat range is considerably dissected by substantial highlands and river valleys. It is possible that the population fragmentation associated with habitat dissection has been sufficient to impose geographical speciation processes on an otherwise robust genetic system.

\section{Acknowledgements}

We wish to thank S. A Carstairs for advice on the electrophoretic technique. This study was conducted while MB held an Australian Postgraduate Research Award.

\section{References}

ANTONOvics, J. 1968. Evolution in closely adjacent plant populations. VI. Manifold effects of gene flow. Heredity, 23, 507-524

BURBidge, A. H. AND WHELAN, R. J. 1982. Seed dispersal in a cycad, Macrozamia riedlei. Aust. J. Ecol. 7, 63-67.

ELlSTRAND, N. C., ORNDUfF R. AND CLEGG J. M. 1990. Genetic structure of the Australian cycad Macrozamia communis (Zamiaceae). Am. J. Bot., 77, 677-681.

HAMRICK, J. L. AND GODT, M. J. w. 1990. Allozyme diversity in plant species. In: Brown, A. H. D., Clegg, M. T., Kahler, A. L. and Weir, B. S. (eds), Plant Population Genetics, Breeding, and Genetic Resources, Sinnaur Associates Inc., Sunderland, MA, pp. 43-63.

JAMES, S. H., WYLIE, A. P., JOHNSON, M.S., CARSTAIRS, S. A. AND SIMPSON, G. A. 1983. Complex hybridity in Isotoma petraea
V. Allozyme varıation and the pursuit of hybridity. Heredity, 51, 653-663.

JOHNSON, L. A. S. 1959 The families of cycads and the Zamiaceae of Australia. Proc. Lin. Soc. New South Wales, 84, 64-117.

LEDIG, F. T. 1986 Heterozygosity, heterosis, and fitness in outbreeding plants. In: Soule, M. E. (ed.), Conservation Biology, Sinauer Associates, Inc., Sunderland, MA, pp. 77-104.

LEWIS, P. AND whitkUS, R. 1989. Genestat-PC. Department of Botany, Ohio State University, Columbus, $\mathrm{OH}$.

MORAN, G. F. AND HOPPER, S. D 1983. Genetic diversity and the insular population structure of the rare granite rock species Eucalyptus caesia Benth. Aust. J. Bot., 31, 161-172.

NEI, M. 1973. Analysis of gene diversity in subdivided populations. Proc. Natl. Acad. Sci., USA, 70, 3321-3323.

NEI, M. 1978. Estimation of average heterozygosity and genetic distance from a small number of individuals. Genetics, 89, 583-590.

NEI, M. AND CHESSER, R. K. 1983. Estimation of fixation indices and gene diversities. Ann. Hum. Genet., 47, 253-259.

RICHARDSON, B. J., BAVERSTOCK, P. R. AND ADAMS, M. 1986. Allozyme electrophoresis. Academic Press, Sydney, pp. 161-218.

SHAW, C. R. AND PRASAD, R. 1970. Starch gel electrophoresis of enzymes - a compilation of recipes. Biochem. Genet, 4 , 297-320

SLATKIN, M. AND BARTON, N. H. 1989. A comparison of three indirect methods for estimating average levels of gene flow. Evolution, 43, 1349-1368.

SWOFFORD, D. L. AND SELANDER, R. B. 1981. BIOSYS-1. A computer program for the analysis of allelic variation in genetics. Department of Genetics and Development, University of Illinois at Urbana-Champaign, Urbana.

VALLEJOS, C. E. 1983. Enzyme activity staining. In: Tanksley, S. D. and Orton, T. J. (eds), Isozymes in Plant Genetics and Breeding Part A, Elsevier Science Publishers B. V., Amsterdam.

WRIGHT, S. 1969. Evolution and the Genetics of Natural Populations, Vol 2. The Theory of Gene Frequencies, University of Chicago Press, Chicago. 